\title{
The Attitudes of Students of Master in Education Regarding the Teaching Profession
}

\author{
Dr. Leticja Papa Gusho \\ Pedagogy-Psychology Department, Social Science Faculty, Tirana University \\ Email:Ipapagusho@yahoo.co.uk
}

Doi:10.5901/ajis.2015.v4n3s1p212

\begin{abstract}
The main aim of this paper is to present a general view of the attitudes of the students of Master in Science in Teaching regarding the teaching profession. The participants in this study were 30 students of the first year attending the Master of Science in Teaching, respectively, from the Natural Science Faculty and the Foreign Language Faculty in Tirana University. From all the population of the students that attend e master degree in teaching in those faculties it was drawn a sample of 30 students through the dimensional sampling method. In this study the qualitative analysis were used, and more specifically, the thematic analysis. The instrument that was used for the gathering of the data was the semi-structured interview. The aim of the interviewing process was to explore and to understand these attitudes. As a conclusion, one of the more important findings of the study is that, a significant percentage of the students liked the teaching profession and wanted to practice this profession in the near future. But they were pessimistic about employment opportunities. According to them, it is very difficult to be employed as teachers in public schools in Albania.
\end{abstract}

Keywords: Students, master of science in education, attitudes.

\section{Introduction}

Albania today is aspiring for its membership in the EU and the Albanian government must meet a lot of standards in different areas. One of these areas is education, where the main aim is to improve all standards in this section.

Thus, in all reforms that are undertaken from the Ministry of Education and Sports, universities that offer preservice training for all level of education, have given a lot of importance to the improving of all curricula of masters in teaching. These new curricula are intended to prepare teachers that are able to face nowadays challenges. These challenges are reworded in numerousness competences that are crucial initially to the new teachers, and later on for all the students that will be taught and prepared from these teachers to be. While all this investment has been made for the preparation of new teachers, and meanwhile in all education undergraduate system is undertaken a very powerful reform to replace exciting teacher centered methods with student centered methods, what is the situation of the attitudes of the students that are studying to be teachers regarding the teaching profession?

In this context, a descriptive qualitative study is undertaken. The main aim of this paper is to present a general view of the approaches of the students of Master of Science in Teaching, regarding the practice of the teaching profession.

\section{Literature Review}

School leaders, teachers, and parents are all concerned about getting and keeping the best teachers for their schools. An introduction to career ladders in teaching has become more viable and attainable. Teachers who have the incentive to continue in education can become staff developers, building administrators, chair-people in their subject areas, and leaders in higher education. The possibility of district-wide appointments that influence school reform in a local, state, and national level can be pursued through easily accessible higher learning institutes. But, most teachers come to their classrooms through traditional routes: that is, an undergraduate pathway that usually involves the study of basic knowledge in the bachelor degree, and a master's degree with an emphasis in childhood, secondary, or special education. Trainees are given a half-year of classroom observation and then the experience of student or teaching practice. Mentoring and supervision are all supposedly part of the program with guided practice and directions before entering their own classroom domains. Even with this experience, and the ability to survive that first year of teaching, a lifetime commitment to classroom teaching has declined over the past 10 years (Mulvey \& Cooper, 2009). 
Tozer et al., (2002), recommended some key ideas for improving teacher preparation for future classrooms. Among the recommendations there were five criteria to address the quality and licensing of teachers: 1 . To make the education of teachers intellectually more solid. 2. To recognize differences in teachers' knowledge, skills, and commitment in their education certification and work. 3. To create standards of entry to the profession-examinations and educational requirements-that are professionally relevant and intellectually defensible. 4 . To connect our institutions to schools (for teacher preparation and development). 5. To make our schools better places for teachers to work and to learn.

New teachers have their common experiences in schools that have similarities in their physical environments, serve students who live near or below the poverty line, and serve communities that are not necessarily connected to or supportive of the school. The effects of poor leadership on the school, peer collegiality and support, interest in student achievement beyond the dreaded assessments, resources, and student attitudes, reflect an atmosphere that has lost the intention of teaching and learning. Johnson (2001) cited in Mulvey \& Cooper (2009), supported the concept of disillusionment of teachers who are attracted to the field of teaching for "the love of learning or the delight of working with children" due to responsibilities that lack the educational flavor and due to lack of support from competent school leaders.

\section{Methodology}

Subjects included in the study. In this study there have participated 30 students. These were students of the first and second year of Master of Science in Teaching from the Foreign Languages Faculty and students of the first and second year of the Master of Science in Teaching from Natural Sciences Faculty. Given that this study was a small scale research, to select the sample a non-probability sample was used and more specifically it was used the dimensional sampling. Dimensional sampling is a further refinement of quota sampling. It involves identifying various factors of interest in a population and obtaining at least one respondent of every combination of these factors (Cohen, Manion \& Morrison, 1970, p 104). For this purpose a sampling plan was built. Sampling plan is a form of a multidimensional table with "branch of the study" across the top and 'year of the study' down the side.

The demographic data was gathered during the phase of personal interviews. The students' ages ranged from 22 to 24 years old, $10 \%$ were male and $90 \%$ were female. The area, from which they came, was another factor that is taken into consideration. $72 \%$ of the students that participated in this study were from urban areas and only $28 \%$ were from rural areas. The exclusion criterion was personal refusal to take part in the study.

Procedure of data collection: The data collection was conducted in two public institutions of higher education. This procedure is done after getting the permission form these institutions. Data were collected in two stages. In the first stage 20 interviews were conducted and all the responses were individual responses according to the aim of the study. The interviews lasted about 40 minutes and were structured in an attempt to identify the students' opinion with respect to the matters of the study. In the second stage two focus groups were formed and each of them had 5 participants. During all the procedure of the data collection the researcher recorded what the participants thought about the issues that contributed to the main aim of the study.

Instrumentation: For the gathering of the data an individual interview was built. The individual interview included 10 questions. All the students were asked to discuss the facts, as they perceived them. The following issues were discussed: Students' expectation regarding the performance of the teaching profession; responsibilities of the profession; tasks that have to be met; their employment opportunities in this profession, etc.

Data analyses: According to Krueger (1994), data analyses in the qualitative studies consist of examining, categorizing, tabulating, or otherwise recording the evidence. The data must be analyzed to address the initial proposition of the study. The depth and intensity of analyses are determined by the purpose of the study. During the first stage, a data analysis is done through exploring the process of all respondents' opinions. Coding and identification of all categories that have emerged from the transcription of non-documentary material is realized during the second stage.

Meanwhile, Stake, (1995), emphasizes that the search of the meaning is a search for patterns. The researcher can look for patterns while reviewing documents, observing or interviewing. Patterns can also be discovered by coding and combining frequencies.

In the last stage of the data analyses, interpretation of the main ideas found is realized through the data and only the interpretation of the real context of the situation was taken into consideration.

Ethics and validity. The way that the research was developed was to minimize non-authentic results. Before conducting the interviews a sensitization of the participant was done and anonymity was guaranteed.

Financial and human resources for this study were very limited and a selection of a small sample violates the 
external validity of the study. As a consequence, results obtained from this study do not represent the entire population of all students who pursue scientific or professional master's degrees in teaching and for this reason generalization can not be made.

Results. The results of this study represent the peak of a working process, based on the processing of information derived from non-documentary materials. The decision to organize the results of the study in its current form has come from the combination of the collected facts examination process and the adjustment of these facts. All this process constitutes in a framework of understanding of all issues being discussed. The results have emerged as a structure which consists of two main topics (MT), in three sub-topics (ST) and in ten categories (C).

A detailed set of results is presented below:

\section{MT1: The students' views about the teaching profession.}

\section{ST1: Commitment in this profession.}

C1: Professional preparation

C2: Methodological preparation

C3: Weaknesses of their education

ST1: Responsibilities in this profession

C1: Willingness to practice this profession

C2: Preparation for responsibilities and duties

C3: Fear of failure

C4: Further qualifications

MT2: The employment situations

ST1: The glass half- full or half- empty

C1: The expectations they have in relation to their employment.

C2: The area in which they like to practice the teaching profession

C3: Difficulties they will face in the employment process

\section{Discussions}

\section{MT1: The students' views about the teaching profession.}

\section{ST1: Commitment in this profession.}

\section{C1: Professional preparation}

The interviews of the students revealed that they are satisfied and feel prepared professionally. They say that during the faculty years they have addressed important professional issues in the branch for which they are going to teach in the future.

\section{C2: Methodological preparation}

For this issue students thought that preparation in this area is very unlimited and knowledge does not end with the completion of the studies. They would like to continue their training in methodological subjects in the future. According to their opinion, all modules they have treated in pedagogical field were very efficient and provided them with the basic skills in this field as well as have trained them to enrich teaching methods, to increase the motivation of students in the classrooms, to be more efficient in classroom management issues, and increase their knowledge in the assessment process. Above all, the modules have been affective in improving their own process of thinking and learning.

One of the students said: I feel good about all I have learned, especially on the aspect of pedagogical training courses.

Subjects such as teaching methodology, classroom management or students evaluation, helped me become more confident as a future teacher.

\section{C3: Weaknesses of their education}

In this category all the problems that students mention as weaknesses of their education were classified. For instance, the foreign language students, mentioned that it would be more appropriate if they had more classes with foreign lecturers. Also, the hearing and active practice that are applied in the higher school should be taken more seriously from all instances, because according to their experience, practice in the proper classrooms is one of the key elements to success in this profession and an experienced teacher acts better and more competently than a teacher without the proper experience.

ST1: Responsibilities in this profession

C1: Willing to practice this profession 
It should be noted that especially female students were really willing to practice this profession. According to them, one of the motivational reasons to practice this profession is the good salary, in both public and private schools. They also wanted to help other people learn and acquire new skills and ways of discovering knowledge. It is worth highlighting that a large number of students who were interviewed were from families where either both parents or one of them were teachers. (This fact was totally casual, it was not involved in the study goals and was discovered during the process of interview).

One of the students interviewed said: - I come from a family where both my parents are teachers. When I was a little girl, I always played games, when I acted as "a really compassionate teacher when I taught" my peers. Now I am completing my studies to be a teacher and I wish to practice this profession. No doubt there are difficulties, as I see in my parents' experience, but I liked it a lot and I can say that I will succeed. I see myself as a very prepared teacher in the future.

\section{C2: Preparation for responsibilities and duties}

According to the opinion of the students practicing the teaching profession it demands engagement in assuming more responsibilities and duties. The teacher has class responsibilities, has to face students, their parents and school principals. Respondents are also aware that such elements like; diversity in teaching methods, task orientation, involvement in the students learning process, and rate of success of students will be a very important part of their future daily work.

\section{C3: Fear of failure}

Students said that teaching in high school is a very difficult job because the standards are very high. Today's youngsters are very clever, very prepared and have sensitive feelings regarding the teacher's performance in the classrooms. For this reason, they thought that more practice in the auditorium would be the best preparation for them and would prepare them not to fail in their fulfillments of duties and responsibilities.

Opinions from the Focus Group: Being a teacher today is very challenging because the student's generations have changed a lot.
We are only 23 or 24 years old and it feels like we are very different from them. In the first years of work, we believe that it is
normal that the teacher will face a lot of difficulties, and perhaps the fear of failure with be present because to work with people,
especially with adolescent is a very challenging duty. Over the years and continuing practice that sensation will be reduced until it
will disappear. Because of their vast experience the senior teachers are very self-confident and they do not have these feelings.

\section{C4: Further qualifications}

For this issue they think that further qualifications are very important for their preparation. They wish to pursue further professional qualification. According to their opinion the institutions responsible for teacher training should be more careful in the training and qualification planning and possibly this training should be free of charge, so that every teacher, despite his/her financial situation, should have possibilities to attend them.

\section{MT2: The employment situations}

\section{ST1: The glass half full or half empty}

C1: The expectations that they have in relation to their employment.

Students are less or not at all optimistic about their employment, and from their perspectives, "the glass is half empty". This situation occurs because, among them there are too many students that are graduated with very good grades, and for them it is very difficult to find work opportunities, especially in the public schools.

One of the students said: I am not very optimistic that I will start work after graduation. My grades are very high but to be honest I
see this issue as very difficult because in my opinion in our country employment does not function according to the merit.
However, if I am not employed in the public schools, I believe that I will find possibilities to be employed in private schools.

\section{C2: The area in which they like to practice the teaching profession}

From the data interviews the students wish to practice their profession as future teachers in the capital city or in the big cities in the country. But among them there are some students, which want to return to their birthplaces and to begin to practice the profession.

One of the students interviewed said: I am from Tirana's suburb and I want to return home and start teaching in the high school that I was graduated myself. I believe that this is an achievable goal because they are short of foreign language teachers. 


\section{C3: Difficulties that will face in the employment process}

For this issue they claim that they will face lengthy and not transparent procedures. Certain instance administrations that are responsible for their involvement in the employment system apply non-transparent procedures. This opinion was stronger among the natural science students focus group.

\section{Conclusion and Recommendation}

This study used qualitative analysis of information collected from 30 subjects. Its core was to explore the attitudes of student teachers regarding the practice of teaching profession.

In this aspect two important general finding should be emphasized.

One of the most significant findings related to this issue is a very positive predisposition of students regarding the teaching profession, thus, a significant percentage of them, want to practice this profession. They feel good, also with their professional preparation, especially with methodological preparation, which according to them has trained them in many directions.

A second critical finding is that most students are less or not at all optimistic about their employment by giving a number of reasons why they feel so. One of the recommendations that can be given at this point is to facilitate employment policies for new teachers.

What new teachers need is sustained, school-based professional development, guided by senior colleagues. Principals and teacher leaders have the largest roles to play in fostering such experiences (Johnson \& Kardos, 2002).

\section{References}

Krueger, R. A. (1994). Focus Groups: A practical guide for applied research. Thousand Oaks. Sage

Stake, R. E. (1995). The art of the case study research. Thousand Oaks. Sage

Mulvey, J. D \& Cooper, B. S. (2009). Getting and Keeping New Teachers: Six Essential Steps from Recruitment to Retention. Rowman \& Littlefield. Publishers.Inc. Retrieved from bokzz.org/book/900210/bd7504

Tozer, S. E., Violas, P. C., \& Senese, G. (2002). School and society: Historical and contemporary perspectives. New York: McGraw-Hill. Johnson, S. M. (2001). Can professional certification for teachers reshape teaching as a career? Phi Delta Kappan.

Johnson, S. M., \& Kardos, S. M. (2002). Keeping new teachers. Educational Leadership, cited in Mulvey, J. D \& Cooper, B. S. (2009). Getting and Keeping New Teachers: Six Essential Steps from Recruitment to Retention. Retrieved from bokzz.org/book/900210 /bd7504

Cohen, L, Manion, L \& Morrison, K.(2005). Research Methods in Education (5 $5^{\text {th }}$ Ed.). Taylor \& Francis Group. 